\title{
A GENERALIZATION OF MUIRHEAD'S INEQUALITY
}

\section{J. B. PARIS AND A. VENCOVSKÁ}

Abstract. We give a proof of a generalization of Muirhead's Inequality and informally explain its application in establishing an instantial relevance principle in Polyadic Inductive Logic.

Mathematics subject classification (2000): 26D15.

Keywords and phrases: Muirhead's Inequality, Counting Partitions, Instantial Relevance.

\section{REFERENCES}

[1] R. CARnaP, A basic system of inductive logic, part 1, in Studies in Inductive Logic and Probability (Volume I), Eds. R. Carnap \& R. C. Jeffrey, University of California Press, Berkeley and Los Angeles, 1971, 33-165.

[2] R. CARnAP, A basic system of inductive logic, in Studies in Inductive Logic and Probability, Volume II, ed. R. C. Jeffrey, University of California Press, 1980, 7-155.

[3] G. H. Hardy, J. E. Littlewood and G. Pólya, Inequalities, Cambridge University Press, 1978.

[4] J. LANDES, J. B. PARIS AND A. VenCOVSKÁ, Language Invariance and Spectrum Exchangeability in Inductive Logic, in Symbolic and Quantitative Approaches to Reasoning with Uncertainty, Proceedings of the 9th European Conference, ECSQARU 2007, Hammamet, Tunisia, Springer LNAI 4724, $151-160$.

[5] J. LANDES, J. B. PARIS AND A. VencovsKÁ, Representation Theorems for probability functions satisfying Spectrum Exchangeability in Inductive Logic, submitted to the International Journal of Approximate Reasoning.

[6] A. W. Marshall I. And Olkin, Inequalities: Theory of Majorization and Its Application, New York, Academic Press, 1979.

[7] R. F. MuIRHEAD, Some methods applicable to identities and inequalities of symmetric algebraic functions of $n$ letters, Proceedings of the Edinburgh Mathematical Society, 21 (1903), 144-157.

[8] C. J. NiX AND J. B. PARIS, A note on binary inductive logic, Journal of Philosophical Logic, 36, 6 (2007), 735-771.

[9] J. B. PARIS, Short course on Inductive Logic, JAIST 2007, available at +http://www. maths. manchester.ac.uk/ jeff/t.

[10] J. B. PARis AND P. WATERHouse, Atom exchangeability and instantial relevance, to appear in the Journal of Philosophical Logic.

[11] P. Waterhouse, Relevance, Irrelevance and Probabilistic Relationships within the Field of Uncertain Reasoning, Ph. D. Thesis, Manchester University, 2007, available at +http://www.maths . manchester.ac.uk/ jeff/+. 